\title{
First report of endovascular treatment of symptomatic coral reef aorta in the aortic arch
}

\author{
Florent Le Bars, MD, ${ }^{\mathrm{a}, \mathrm{c}, \mathrm{d}}$ Etienne Charbonneau, MD, ${ }^{\mathrm{b}}$ Guillaume Leurent, MD, ${ }^{\mathrm{b}}$ and \\ Adrien Kaladji, MD, PhD, ${ }^{\mathrm{a}, \mathrm{c}, \mathrm{d}}$ Rennes, France
}

\footnotetext{
From the Departements of ${ }^{\mathrm{a}}$ Cardiothoracic and Vascular Surgery and ${ }^{\mathrm{b}}$ Cardiology, CHU Rennes; ${ }^{\mathrm{c}}$ INSERM, U1099; and ${ }^{\mathrm{d}}$ Signal and Image Processing Laboratory (LTSI), University Rennes 1, Rennes, France.

Disclosures: Dr Kaladji reported proctoring activity for Cook, W. L. Gore \& Associates, and Medtronic. Dr Leurent reported proctoring activity, lecture, and consultant fees for Abbott. All other authors reported no conflicts of interest.

The Journal policy requires editors and reviewers to disclose conflicts of interest and to decline handling or reviewing manuscripts for which they may have a conflict of interest. The editors and reviewers of this article have no conflicts of interest.

Received for publication Sept 27, 2021; accepted for publication Jan 12, 2022; available ahead of print Jan 19, 2022.

Address for reprints: Florent Le Bars, MD, Department of Thoracic and Cardiovascular Surgery, Centre Hospitalier Universitaire Pontchaillou, 2 rue Henri le Guilloux, 35000 Rennes, France (E-mail: flo_lebars@ @otmail.fr). JTCVS Techniques 2022;12:17-20

2666-2507

Copyright (c) 2022 The Author(s). Published by Elsevier Inc. on behalf of The American Association for Thoracic Surgery. This is an open access article under the CC BY-NC-ND license (http://creativecommons.org/licenses/bync-nd/4.0/).

https://doi.org/10.1016/j.xjtc.2022.01.010
}

A 64-year-old female patient was treated in the Cardiology Intensive Care Unit due to decompensated heart failure with a left ventricular ejection fraction of $10 \%$. She did not present with any serious history, other than a body mass index of 15.4 with $10 \mathrm{~kg}$ of weight loss in 6 months. A cardiac magnetic resonance imaging scan was performed and identified low signal intensity at the aortic arch, which led to aortic computed tomography angiography being performed. This found a 95\% preocclusive limestone bud in zones 2 and 3 of the aortic arch protruding into the ostium of the left subclavian artery (Figures 1 and 2). Findings of a transthoracic ultrasound scan revealed dilated (left ventricular end-diastolic diameter $70 \mathrm{~mm}$ ), nonhypertrophic, biventricular cardiomyopathy, with recovery of left ventricular ejection fraction of $18 \%$ under diuretic and dobutamine treatment. A nonmobile, left apical intraventricular thrombus measuring $19 \mathrm{~mm}$ was also identified and a pressure gradient across the isthmus of $64 \mathrm{~mm} \mathrm{Hg}$ with a Vmax of $4 \mathrm{~m} / \mathrm{s}$ consistent with acquired coarctation of the aorta, which is likely responsible for the cardiac dysfunction because no other cause was identified during the investigations (normal coronary angiogram). Moreover, this clinical picture was also associated with abdominal angina and diarrhea, of hemodynamic origin with a low flow rate, responsible for the extreme weight loss and the suppression of the femoral pulses. Due to the aortic lesion and the severe malnutrition, open surgery (arch replacement or heart transplant) was contraindicated by the medical staff.

By sizing the aorta using the EndoSize software (Therenva, Rennes, France), we were able to identify a circulating

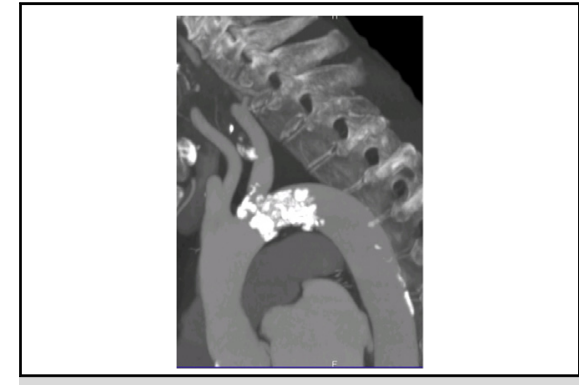

Sagittal view of the isthmic coralliform lesion.

CENTRAL MESSAGE

The first report of endovascular treatment of symptomatic coral reef aorta in the aortic arch is presented.

See Commentary on page $\mathbf{2 1}$.

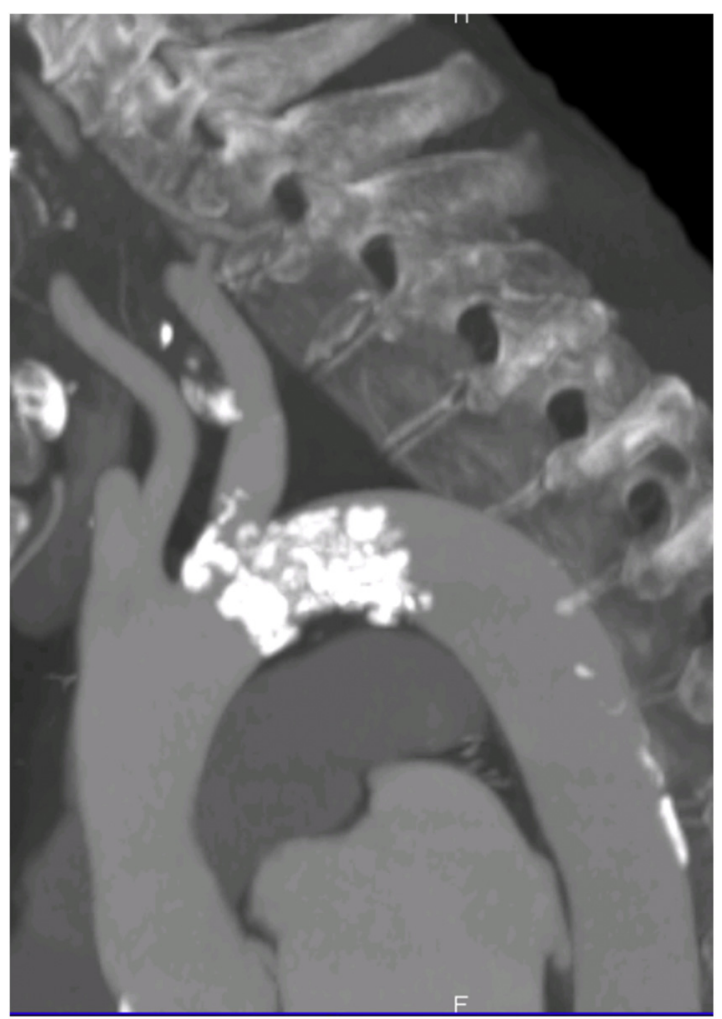

FIGURE 1. Sagittal view of the isthmic coralliform lesion. 


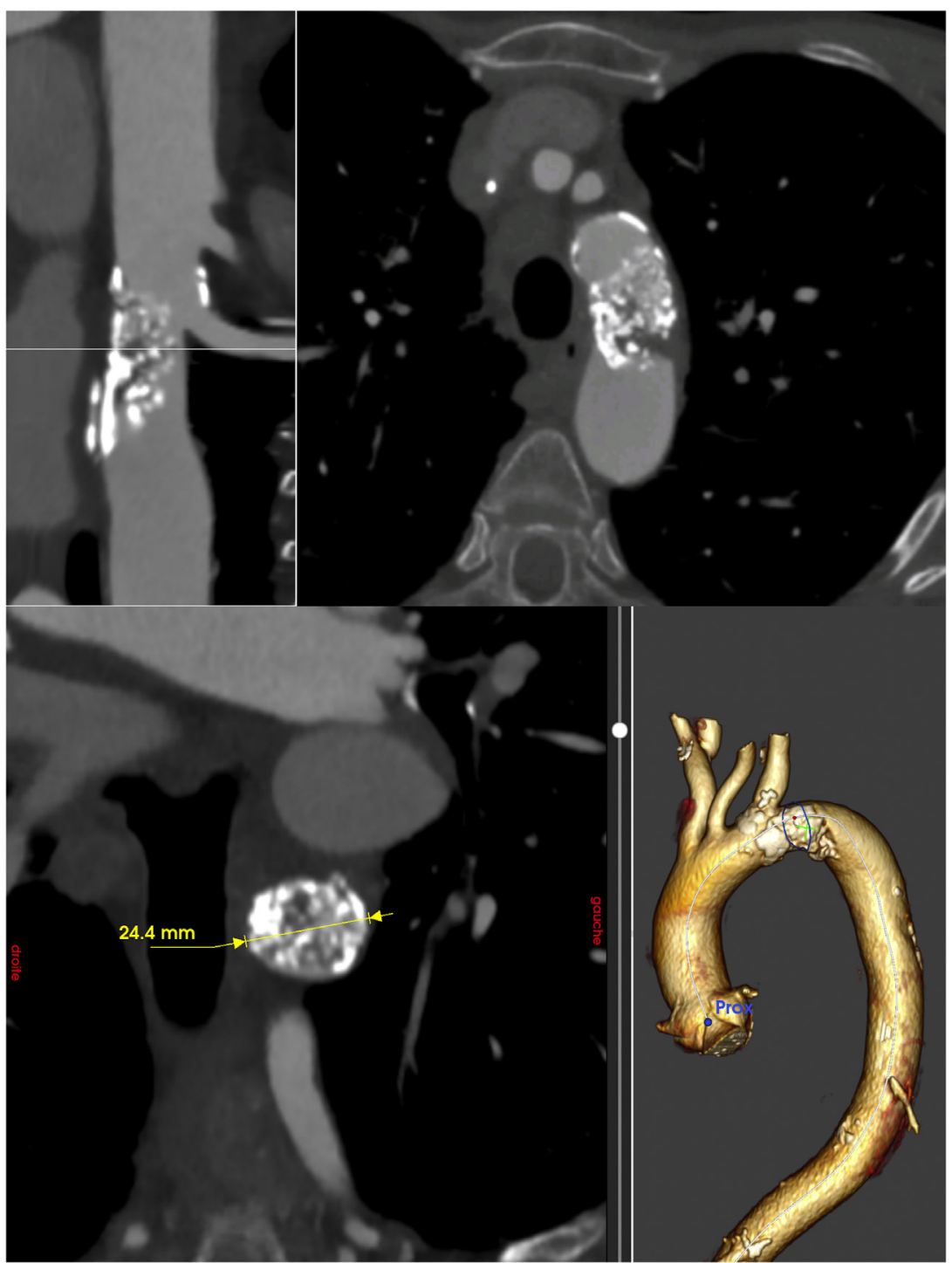

FIGURE 2. Straight views, orthogonal, and 3-dimensional reconstruction of the aortic arch stenosis.

channel measuring $1.5 \mathrm{~mm}$ at the superior part of the lesion in contact with the large aortic curvature, which opened the door to endovascular management. It was decided to use an undersized aortic stent and not to use a stent of a nominal aortic diameter due to the high risk of rupture when it is deployed. The choice was therefore focused on a strong stent with the benefit of a better radial force and a covered stent to prevent bleeding from possible wall lesions when the balloon is inflated. Given the lesions at the ostium of the left subclavian artery and the risk of overlapping them with the covered aortic stent, it was also decided to stent the left subclavian artery.

The intervention was performed under general anesthesia with right-side femoral access and surgical approach via the left brachial artery. The angiography confirmed the extent of the lesion and the resulting reduction in blood flow speed.
Stenting of these lesions was carried out with 2 covered cobalt chromium stents (BeGraft Peripheral Stent Graft $8 \times 57 \mathrm{~mm}$; Bentley Innomed $\mathrm{GmbH}$, Hechingen, Germany) using a chimney technique with simultaneous deployment and kissing balloon inflation (Figure 3). Given the patient's fragility and severe left ventricular ejection fraction impairment, a temporary pacing electrode was not used. The follow-up angiography found that the stents were correctly deployed without there being any associated stenosis and that there was good flow in the left subclavian artery and in the aorta (Figure 4).

On day 5 after the surgery, dobutamine was stopped and an ultrasound scan of the heart and aorta found a left ventricular ejection fraction of $20 \%$ without catecholamine support, a decrease of almost $50 \%$ in the pressure gradient across the isthmus, from 64 to $33 \mathrm{~mm} \mathrm{Hg}$, and the 


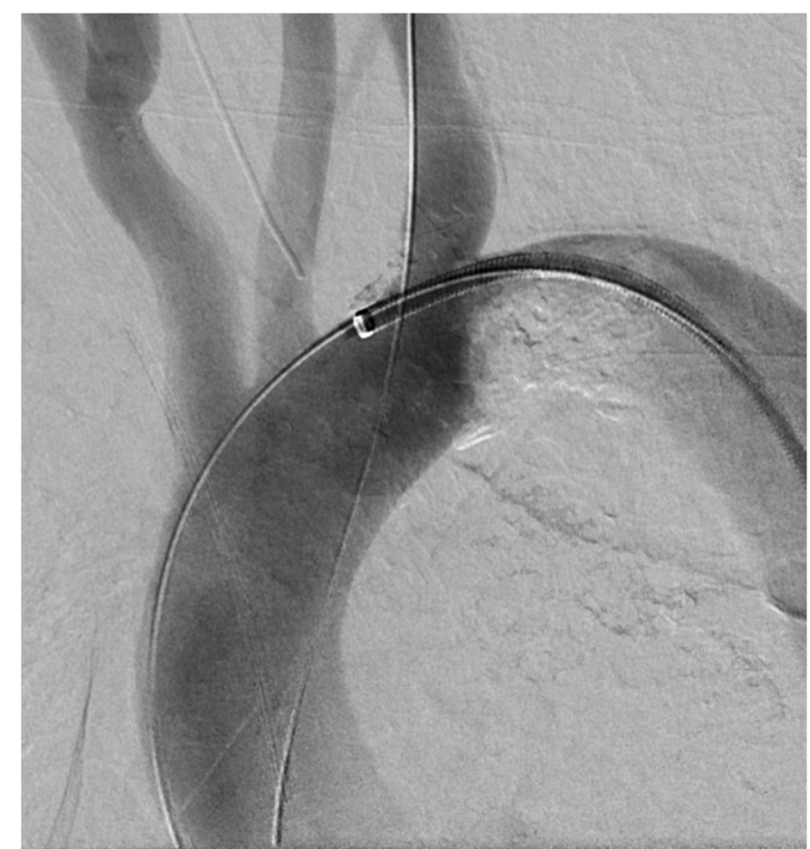

FIGURE 3. Positioning of the guides through the lesions before inflation of the stents by the chimney technique.

amendment of the mesenteric angina. At 5 months, the mean gradient was unchanged at $33 \mathrm{~mm} \mathrm{Hg}$, but the left ventricular excretion fraction was significantly improved to $39 \%$.

\section{DISCUSSION}

Unlike porcelain aortas with parietal, circumferential, and multistage involvement, intra-aortic coral reef lesions are intraluminal and localized to the healthy aorta. These are rare but severe lesions that are often associated with surgical management by means of transaortic endarterectomy or extra-anatomic bypass. The origin of these lesions is unclear, but the most likely hypothesis is the secondary calcification of a thrombus. They most often affect young women, in a ratio of 1.6:1. Their prevalence is between $0.6 \%$ and $1.8 \%$ of the population, and they are predominantly found in the abdominal region and very rarely in the aortic arch. Only 3 cases in the isthmus have been identified in the literature. One of these 3 cases was not managed surgically due to the severity of the cardiac impairment, which led to the patient's death due to cardiogenic shock. ${ }^{1}$ The 2 other cases, with maintained ejection fraction but myocardial hypertrophy, benefited from successful open surgery on the aortic arch., In our case, open surgery was not conceivable due to the cardiac impairment. Given the favorable anatomy, we focused on endovascular management. After reviewing the literature, it became apparent

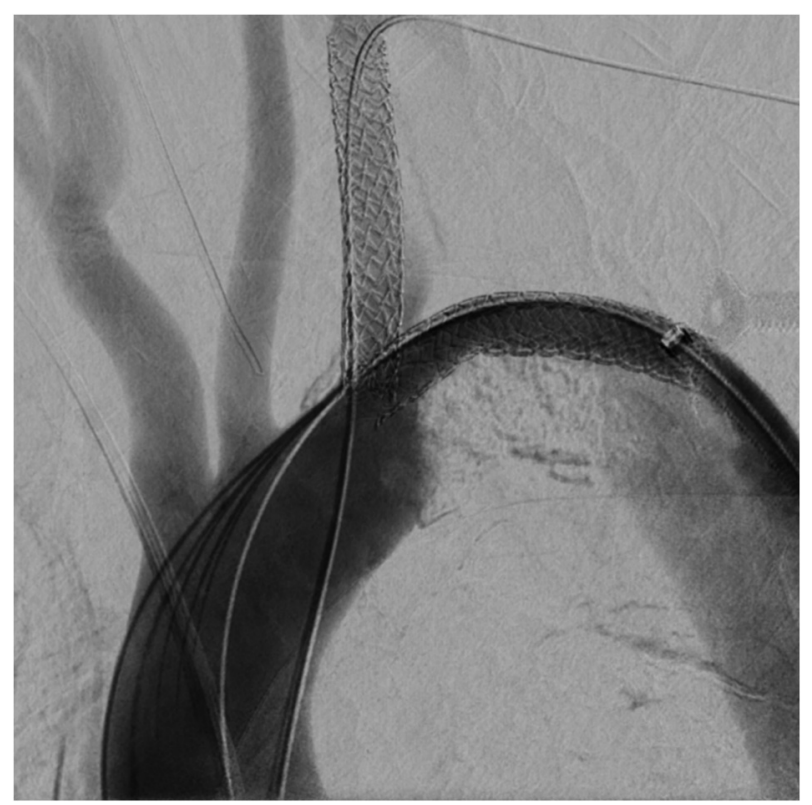

FIGURE 4. Per-procedural control angiography after placement of stents in the aortic arch and departure of the left subclavian artery.

that this management had not been described previously at the level of the aortic arch. Endovascular management has only been described for lesions affecting the thoracoabdominal junction, and in those cases a covered stent was inserted using the thoracic endovascular aneurysm repair (TEVAR) technique.

Some cases of heart failure have been described in combination with intra-aortic coral reef lesions, of which one affected the aortic arch, ${ }^{1}$ and 2 were at the thoracoabdominal junction. ${ }^{4,5}$ Unlike our case, the cardiac cases were hypertrophic and not dilated due to the increased afterload caused by the intra-luminal obstacle that the blood flow came up against. Berger and colleagues ${ }^{5}$ describe, like us, immediate cardiac recovery following removal of the lesion.

Like any endovascular procedure, the placement of stents exposes them to complications. In this case, the risk of stent migration is reduced due to the hooks provided by the limestone bud, the risk of stent rupture is limited by the placement of a stent of undersized caliber compared with the size of the aorta, and the risk of endoleak, although possible due to calcifications, does not confer any complication in this case because the aim was not a seal but a recanalization.

Because this is an observational work, institutional review board approval was not necessary; however, we had the authorization of the CNIL (Commission nationale de l'informatique et des libertés) in 2017, under the number 1207754, for the data collection. Patient consent was obtained to include their information in this publication. 


\section{References}

1. Verreault-Julien L, Beaudoin J, Thériault M-M, Do DH. Case report of an unusual and catastrophic presentation of coral reef aorta. Eur Heart J Case Rep. 2019;3: yty 163 .

2. Palcau L, Gouicem D, Cameliere L, Berger L. Calcified obstructive disease of the aortic arch. Interact Cardiovasc Thorac Surg. 2014;18:683-4.
3. Karakattu S, Murtaza G, Dinesh S, Sivagnanam K, Schoondyke J, Paul T. Super sized atheroma causing acquired coarctation of aorta leading to heart failure. J Investig Med High Impact Case Rep. 2017;5:232470961668947.

4. Satsu T, Saga T, Kaneda T, Imura M. Congestive heart failure due to coral reef thoracoabdominal aorta. Interact Cardiovasc Thorac Surg. 2011;13:684-5.

5. Berger L, Coffin O, Saplacan V, Pellissier A, Belin A. Aortic coral reef as an unusual possible cause of heart failure. Int J Cardiol. 2014;177:e113-4. 